\title{
Genome-Wide Association Study of Spot Form of Net Blotch Resistance in the Upper Midwest Barley Breeding Programs
}

\author{
R. R. Burlakoti, S. Gyawali, S. Chao, K. P. Smith, R. D. Horsley, B. Cooper, G. J. Muehlbauer, and S. M. Neate
}

First and second authors: Department of Plant Pathology, North Dakota State University, NDSU Dept. 7660, P.O. Box 6050, Fargo 58108-6050; third author: U.S. Department of Agriculture-Agricultural Research Service Cereal Crops Research Unit, 1605 Albrecht Blvd., Biosciences Research Laboratory, Fargo, ND 58105-5674; fourth and seventh authors: Department of Agronomy and Plant Genetics, University of Minnesota, 411 Borlaug Hall, 1991 Upper Buford Circle, St. Paul 55108-6026; fifth author: Department of Plant Sciences, North Dakota State University, NDSU Dept. 7670, P.O. Box 6050, Fargo 58108-6050; sixth author: Busch Agricultural Resources Inc. (BARI), 3515 E. Richards Lake Rd., Ft. Collins, CO 80524; and eighth author: Centre for Crop Health, University of Southern Queensland, Toowoomba, QLD 4350, Australia.

Current address of first author: World Vegetable Center, P.O. Box 42, Shanhua, Tainan, 74151 Taiwan.

Current address of second author: International Center for Agricultural Research in Dry Areas (ICARDA), INRA-M Institut, Rue Hafiane

Cherkaoui, Rabat 10112, Morocco.

Accepted for publication 15 August 2016.

\begin{abstract}
Pyrenophora teres f. maculata, the causal agent of spot form of net blotch (SFNB), is an emerging pathogen of barley in the United States and Australia. Compared with net form of net blotch (NFNB), less is known in the U.S. Upper Midwest barley breeding programs about host resistance and quantitative trait loci (QTL) associated with SFNB in breeding lines. The main objective of this study was to identify QTL associated with SFNB resistance in the Upper Midwest two-rowed and six-rowed barley breeding programs using a genome-wide association study approach. A total of 376 breeding lines of barley were evaluated for SFNB resistance at the seedling stage in the greenhouse in Fargo in 2009. The lines were genotyped with 3,072 single nucleotide polymorphism (SNP) markers. Phenotypic evaluation showed a wide range of variability among populations from the four breeding programs and the two barley-row types. The two-rowed barley

resistance. The mixed linear model (MLM) analysis, which included both population structure and kinship matrices, was used to identify significant SNP-SFNB associations. Principal component analysis was used to control false marker-trait association. The linkage disequilibrium (LD) estimates varied among chromosomes $(10$ to $20 \mathrm{cM})$. The MLM analysis identified 10 potential QTL in barley: $S F N B-2 H-8-10, S F N B-2 H-38.03, S F N B-3 H-58.64$, SFNB-3H-78.53, SFNB-3H-91.88, SFNB-3H-117.1, SFNB-5H-155.3, $S F N B-6 H-5.4, S F N B-6 H-33.74$, and $S F N B-7 H-34.82$. Among them, four QTL (SFNB-2H-8-10, SFNB-2H-38.03 SFNB-3H-78.53, and SFNB-3H117.1) have not previously been published. Identification of SFNB resistant lines and QTL associated with SFNB resistance in this study will be useful in the development of barley genotypes with better SFNB resistance.
\end{abstract} lines were more susceptible to SFNB than the six-rowed lines. Continuous distributions of SFNB severity indicate the quantitative nature of SFNB
Additional keywords: association mapping, Hordeum vulgare.
The barley net blotch pathogen, Pyrenophora teres, has two forms: Pyrenophora teres f. maculata Smed.-Pet., which produces spot form of net blotch (SFNB) and Pyrenophora teres f. teres Drechsler, which produces net form of net blotch (NFNB). SFNB has been reported in many barley growing areas of the world including Canada (Tekauz 1990; Turkington et al. 2011), South Africa (Campbell et al. 1999; Louw et al. 1996), Australia (McLean et al. 2009), and Europe (Tuohy et al. 2006). The disease caused yield losses of 20 to $30 \%$ in susceptible cultivars in western Canada (van den Berg and Rossnagel 1991) and up to 40 to $56 \%$ in Australia (McLean et al. 2009).

Compared with NFNB, SFNB was not historically considered as an economically important disease. However, the incidence of SFNB has increased considerably in recent years in barley growing areas of North America, South Africa, and Australia (McLean et al. 2009; Turkington et al. 2011). In Canada, SFNB incidence has been reported in all three Prairie Provinces (Tekauz 1990; Turkington et al. 2011), with yield losses in those regions up to $20 \%$ from SFNB in combination with other foliar diseases (Turkington et al. 2011). In

Corresponding author: R. R. Burlakoti; E-mail address: rrburlakoti@gmail.com

*The $\boldsymbol{e}$-Xtra logo stands for "electronic extra" and indicates that one supplementary table is published online.

(C) 2017 The American Phytopathological Society the United States, SFNB severity was reported in susceptible barley cultivars in Montana during 1980s (Bockelman et al. 1983; Karki and Sharp 1986). In 2007 and 2008 in the barley growing areas of North Dakota (ND), symptoms were observed that were similar to spot blotch (Cochliobolus sativus) symptoms in spot blotch resistant cultivars. Those symptoms were identified as SFNB, confused with spot blotch (S. Neate, personal observation). P. teres f. maculata was isolated from those infected barley leaves, but no Cochliobolus sativus was isolated. The P. teres f. maculata isolates produced spot form of net blotch symptoms on barley when inoculated in the greenhouse. Liu et al. (2011) and Liu and Friesen (2010) subsequently published a report of an increase in SFNB incidence in ND in recent years. The disease is favored by cool night temperatures in combination with leaf surface wetness and high relative humidity (van den Berg and Rossnagel 1991) and either climatic changes from 2007 onward resulted in the resurgence of the disease in the U.S. Upper Midwest barley growing areas or a mutation to a more virulent or aggressive form of the pathogen took place, as barley cultivars are changed infrequently and there was no major shift in cultivars sown around 2005 to 2008.

Of the management practices available to control crop diseases, the use of host resistance is generally cost free and can be an effective approach. Since SFNB has been considered a less important disease of barley in the Upper Midwest of the United States in past years, very limited studies have been conducted to identify variation in 
resistance to the disease in the current breeding programs in the Upper Midwest. Because of the many and stringent morphological and quality traits that must be retained in malting barley compared with other cereals, the breeding programs are quite narrow (Mikel and Kolb 2008) and utilizing resistance from within the existing breeding populations is preferred.

Compared with biparental mapping, association mapping has several advantages (Gupta et al. 2005; Zhu et al. 2008). For example, association mapping uses existing germplasm, cultivars, landraces, or breeding lines, and therefore, eliminates the time and cost of developing a mapping population. Additionally, mapping resolution can be higher in association mapping compared with traditional biparental mapping because the population used in association mapping can exploit higher frequencies of recombination which have occurred over many generations (Zhao et al. 2007). Association mapping has been used to identify quantitative trait loci (QTL) associated with resistance for several diseases of barley including rust (Steffenson et al. 2007), Fusarium head blight (Massman et al. 2011), common root rot (Gyawali 2010), and spot blotch (Roy et al. 2010).

Using biparental mapping approach, major and minor QTL associated with SFNB resistance have been identified in barley including Rpt4 on chromosome 7H (Williams et al. 1999), Rpt6 on chromosome 5H (Manninen et al. 2006), QRpts4, QRpt6, and QRpt7 on chromosomes $4 \mathrm{H}, 6 \mathrm{H}$, and 7H, respectively (Grewal et al. 2012), and QRptms1, QRptm2, QRptms4, and QRptms6 on chromosomes 1H, $2 \mathrm{HL}, 4 \mathrm{H}$, and $6 \mathrm{H}$, respectively (Grewal et al. 2012). An association mapping approach using a U.S. Department of Agriculture barley core collection and a North Dakota isolate revealed one marker on chromosome $1 \mathrm{H}$, two on chromosome $2 \mathrm{H}$, six on chromosome $3 \mathrm{H}$, one on chromosome $4 \mathrm{H}$, two on chromosome $5 \mathrm{H}$, four on chromosome $6 \mathrm{H}$, and four on chromosome 7H (Tamang et al. 2015). Four of these QTL were close to previously published QTL Rpt6, QRpt6, Rpt4, or $R p t 7$. An association mapping approach was also used on four tworowed barley populations from an Australian breeding program which included advanced lines from different generations, international introductions and cultivars (Wang et al. 2015). Nineteen QTL were significantly associated with seedling or adult plant stages resistance in at least three of the four tested populations.

This study is a part of the barley Coordinated Agricultural Project (CAP) and uses a genome-wide association mapping approach to identify single nucleotide polymorphism (SNP) markers associated with SFNB resistance in barley. The barley CAP is a community approach of collaborative research projects for genome-wide association studies to identify QTL associated with important phenotypes of barley such as, yield, food, malting quality, and disease resistance, with the ultimate aim of utilizing the technique in U.S. barley breeding programs (Hayes and Szucs 2006; Waugh et al. 2009). The specific objectives of this research were (i) to examine the phenotypic diversity of barley CAP 2006 lines from Upper Midwest Barley Breeding Program for seedling resistance to SFNB, and (ii) to identify QTL associated with SFNB resistance in barley using association genetics. The identification of QTL or SNP significantly associated with SFNB resistance will assist the development of barley genotypes with resistance to spot form of net blotch.

\section{MATERIALS AND METHODS}

Plant materials. A population of 376 advanced breeding lines from four barley breeding programs in the Upper Midwest of United States was used in the current study. The barley genotypes included in the study were offered in 2006 to the barley CAP. The population comprised 94 lines of six-rowed spring barley lines from the University of Minnesota (UM), 64 lines of two-rowed spring barley from Busch Agricultural Resources LLC (BA2), 31 lines of six-rowed spring barley from Busch Agricultural Resources LLC (BA6), 91 lines of six-rowed barley from North Dakota State University (ND6), and 96 lines of two-rowed spring barley from North Dakota State University (ND2). All barley lines were inbred lines of at least $\mathrm{F}_{4}$ generation and selected for uniform agronomic traits.

Phenotypic evaluation for SFNB resistance. Two independent greenhouse experiments were laid out in a randomized complete block design (RCBD) with three replicates in each experiment. Barley genotypes were grown in the greenhouse at Fargo, ND and temperatures were maintained at 22 to $25^{\circ} \mathrm{C}$ with a photoperiod of $14 \mathrm{~h}$ light and $10 \mathrm{~h}$ dark with supplemental lighting provided by $1,000 \mathrm{~W}$, metal halide bulbs (530 to $710 \mu \mathrm{mol} \mathrm{m}^{-2} \mathrm{~s}^{-1}$ ) (P. L. Light Systems, Beamsville, ON, Canada). Five seeds of each line were sown in a Ray Leach "Cone-tainer" $3.8 \mathrm{~cm}$ diameter $\times$ $14 \mathrm{~cm}$ depth (Stuewe \& Sons Inc., Oregon) (the experimental unit) filled with Sunshine mix no. 1 (Sun Gro Horticulture, Agawam, Massachusetts) and plants were fertilized (3 $\mathrm{g} \mathrm{liter}^{-1}$ of 15-30-15 Miracle Gro, Scotts, Port Washington, NY) as needed.

Isolates of the SFNB pathogen (P. teres f. maculata) were isolated in 2009 from SFNB diseased barley leaves provided by J. Menert (Busch Agricultural Resources LLC) collected from Fairview, Montana on the border with ND. The infected leaf tissues were surface sterilized with $5 \%$ sodium hypochlorite $(\mathrm{NaClO})$ and incubated in petri dishes with moist filter paper for $48 \mathrm{~h}$ in a cycle of $12 \mathrm{~h}$ near UV + fluorescent white light alternating with $12 \mathrm{~h}$ dark. Single spore isolates were made and grown in V8 agar ( $100 \mathrm{ml}$ of V8 juice, $3 \mathrm{~g}$ of $\mathrm{CaCO}_{3}$, and $10 \mathrm{~g}$ of agar) for 7 to 8 days. To produce inoculum, single spore isolates were transferred to Petri dishes of barley agar media (20 g of agar and $5 \mathrm{~g}$ of fresh barley leaves in 1 liter of distilled water and sterilized by autoclaving) for 2 weeks at room temperature with a $12 \mathrm{~h}$ near UV + fluorescent white light alternating with dark cycle. Fungal cultures were flooded with sterile distilled water, scraped with a sterile glass rod and poured into a sterile beaker. Two drops of Tween 20 (polyoxyethylene sorbitan monolaurate) were added to $100 \mathrm{ml}$ of the conidial suspension. The conidia were counted using a hemocytometer and the final concentration of fungal spores was adjusted to $5 \times 10^{3}$ conidia/ml.

Two preliminary experiments were conducted to evaluate nine genotypes for SFNB resistance. The objectives of the preliminary study were to determine the appropriate conditions for screening of seedling resistance to SFNB in the greenhouse and also to verify the virulence of isolates. Nine genotypes in the study included one susceptible check ('Harrington', Williams et al. 2003) and one resistant check (CI9819, Ethiopian two-rowed barley line, Manninen et al. 2006), spot blotch resistant check (NDB-112), the Septoria passerinii resistant line 'CIho 10644' and four other barley cultivars ('Bowman', 'Hector', 'Reka', and 'Manchuria'). The virulence of the new isolate was also compared with a previously characterized SFNB isolate 'ONT1049' (provided by A. Tekauz, Agriculture and Agri-Food Canada, Winnipeg, Canada) isolated from the susceptible barley cultivar 'Harrington'. Both isolates produced similar spot form net blotch symptoms on the nine check genotypes; however, the new isolate produced more severe SFNB infection than ONT1049. The new isolate named 'SFNB-MT09' was selected for further screening of barley CAP genotypes.

After preliminary experiments, $376 \mathrm{CAP}$ lines and nine genotypes described in the above paragraph were evaluated for SFNB resistance. The two to three leaf stage of barley seedlings were inoculated with a suspension of spores from 12- to 14-day-old cultures (5,000 conidia $\mathrm{ml}^{-1}$ suspension) using an atomizer (DeVilbiss Health Care, Inc., Somerset, PA) pressured at 25 to $30 \mathrm{kPa}$. Spray inoculation was continued until run off. The seedlings were dried at room temperature for 20 to $30 \mathrm{~min}$ and then incubated in chambers humidified with ultrasonic misters (HM-470, HOLMES Product Corporation, Milford, MA), $10 \mathrm{~s}$ continuous misting at $4 \mathrm{~min}$ intervals for $24 \mathrm{~h}$ in the dark at $21^{\circ} \mathrm{C}$. After $24 \mathrm{~h}$ incubation in the misting chamber, the plants were slowly dried at room temperature. Once the plants were dried, they were transferred in the greenhouse bench and the greenhouse 
environment was set as described earlier. The SFNB severity was assessed 10 to 12 days after inoculation using a slight modification of the rating scale ( 1 to 9) developed by Tekauz (1985). Symptoms of small necrotic spots with small surrounding chlorotic areas were rated as a resistant reaction (scale 1 to 3), whereas large distinct necrotic spots surrounded by chlorosis which expanded with time were rated as a susceptible reaction (scale 7 to 9). A necrotic spot surrounded by small to moderate chlorotic halos was rated as scale 5. The rating scale was the same as that described by Tekauz (1985), however a slight modification was made in defining resistant and susceptible reactions. Tekauz (1985) categorized scale 5 as a moderately resistant to moderately susceptible and there was no scale for 4 and 6 . However, values of 4 and 5 were obtained when mean values in each line (five plants per line) were calculated. Therefore, plants with a mean rating of $<3$ and 3 to 5 were categorized as resistant and moderately resistant, whereas plants with a disease reaction of $>5$ to 7 and $>7.0$ were categorized as moderately susceptible and susceptible reaction.

Phenotypic data analysis. A total of 30 seedlings of each line (five plants in the experimental unit $\times$ two independent experiments $\times$ three replicates) were rated for SFNB severity and the mean was calculated. Mean and standard deviation of SFNB severity were then calculated for each line in the mapping population. Analysis of variance (ANOVA) of SFNB severity was performed for each

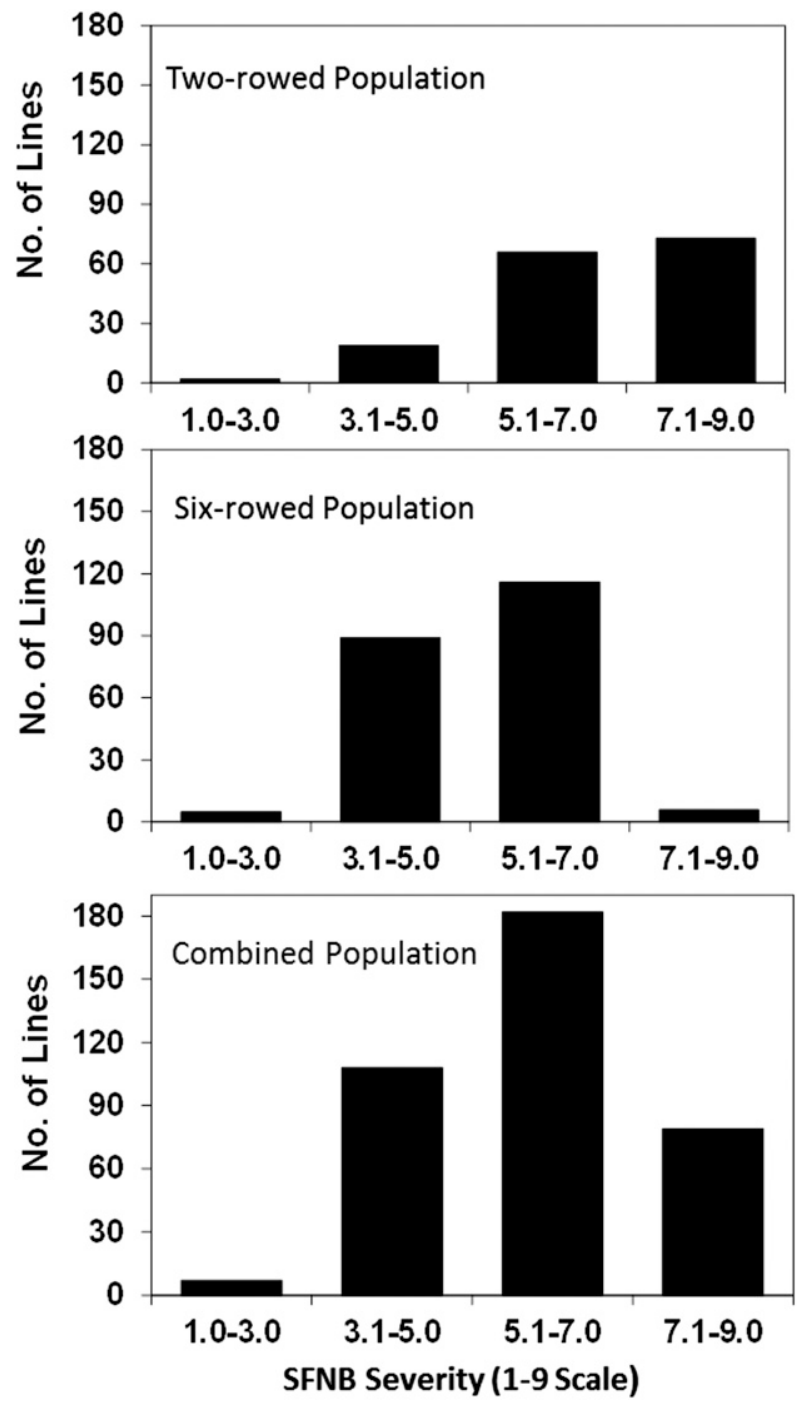

Fig. 1. Phenotypic distribution of seedling resistance to spot form of net blotch (SFNB) for the barley Coordinated Agricultural Project 2006 lines from the Upper Midwest of the United States. Numbers of lines were 376 in combined population, 160 in two-rowed subpopulation, and 216 in six-rowed subpopulation. greenhouse experiment using SAS (version 9.1, Statistical Analysis System; SAS Institute, Cary, NC). Homogeneity tests of error variance between the two greenhouse experiments were also performed. Since data of both experiments were homogenous, the combined mean values of SFNB severity from both experiments were used to analyze association between SFNB resistance and SNP markers.

Genotyping of the barley germplasm. The genotyping of the 376 barley CAP lines was done in the USDA-ARS Genotyping Laboratory in Fargo, ND. The DNA was extracted from a single seedling of each line using the method of Slotta et al. (2008). The barley lines were genotyped using 3,072 SNP markers (Close et al. 2009). The 3,072 SNP markers were designed from a barley oligonucleotide pool assay using expressed sequence tags. All 3,072 SNP markers were filtered to eliminate potential errors in allele calls of the SNP markers with $>10 \%$ missing data points and $<5 \%$ minor allele frequency. These filtered SNP data were subsequently used for analysis of population structure, linkage disequilibrium, and association mapping. The data, marker information, and SNP alleles are available in barley CAP (www.hordeumtoolbox.org) and/or T3 barley websites (https://triticeaetoolbox.org/barley/). The significant marker allele state (A, T, G, and C) as well as sequences are also provided in Supplementary Table S1.

Population structure analysis. Principal component analysis (PCA) was performed in TASSEL 2.1 and P-matrices were generated using the filtered SNP data. PCA was used to account for population structure and genetic variation caused by allele frequency differences in mapping populations. The top $10 \mathrm{PCs}$ which explained $>50 \%$ genotypic variation were used as covariates in association analysis. The kinship matrix was generated in TASSEL 2.1 using filtered SNP marker data (Lynch and Ritland 1999). The PCA assignments (P-matrix) and coefficient of kinship matrix (K, measure of relative kinship) were combined and used as covariates in the mixed linear model (MLM) in the association analysis.

Linkage disequilibrium (LD). Using pair-wise comparisons among filtered SNP markers, the genome wide LD were analyzed in TASSEL 2.1. The LD values were estimated using Pearsons' coefficient $\left(r^{2}\right)$ between pairs of SNP markers (Pritchard and Przeworski 2001). Using SAS, the LD decay plots were generated using $r^{2}$ values as a function on genetic distance (cM) of markers. The LD pattern for SNP markers were analyzed for each chromosome. The value of $r^{2}=0.2$ was considered as average threshold value of LD for the combined population and subpopulations based on row types.

Association analysis. The association analysis was performed in TASSEL 2.1 (Bradbury et al. 2007) for the combined two-rowed and six-rowed population $(n=376)$ and two subpopulations designated based on row-type, the two-rowed subpopulation $(n=$ $160)$, and the six-rowed subpopulation $(n=216)$. Associations between the SFNB resistance and SNP markers were analyzed using MLM (Zhao et al. 2007). The MLM included both population structure (P-matrices generated in PCA analysis) and kinship coefficient (K-matrices) in association analysis. The genotypic data (using filtered SNP's), phenotypic data (SFNB severity data), P-matrices and K-matrices were used in the MLM analysis. The default run parameters of MLM were used except that the analysis method was set to expectation maximization (EM). SNPs having $P$ values of $\leq 0.001$ were declared significant markers associated with SFNB resistance. Furthermore, the positive false discovery rate (pFDR) was calculated in SAS 9.2 using procedure described by Storey (2002). The SNPs with pFDR $q$ value of $\geq 0.13$, were declared a false positive. We used the genome-wide association study (GWAS) approach described by Kraakman et al. (2004). In this approach, association between SNP markers and SFNB resistance phenotypes were analyzed, thereafter LD values were calculated across genomes for mapping populations, chromosomewide association profiles with $-\log (P)$ of SFNB-resistance markers for all three mapping populations were generated, and finally 
flanking markers of trait-associated markers were examined while scanning QTL associated with SFNB resistance in different chromosomes.

\section{RESULTS}

Phenotypic evaluation. Phenotypic evaluation showed a wide range of variability in SFNB infection response ( 0 to 9 scale) in both six-rowed (range 2.5 to 7.6 ) and two-rowed (range 2.3 to 8.6 ) barley subpopulations. ANOVA showed a significant difference $(P<$ 0.001 ) in seedling resistance to SFNB among the barley genotypes in both the two-rowed and the six-rowed subpopulations. A

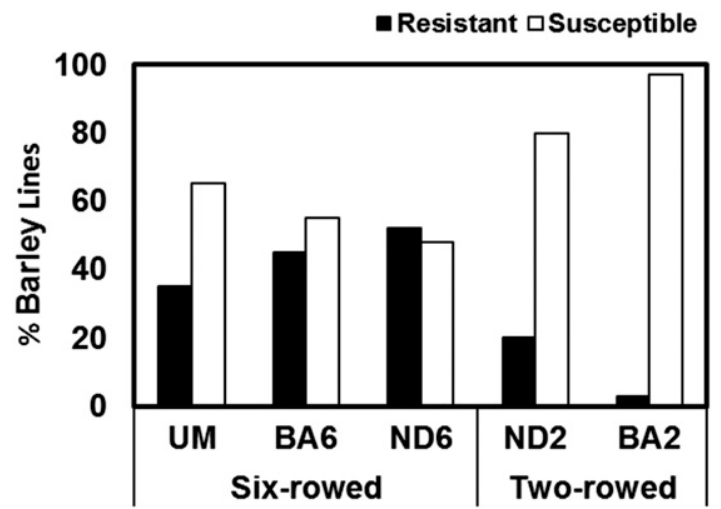

Fig. 2. Variation in seedling resistance to spot form of net blotch (SFNB) on two-rowed and six-rowed barley Coordinated Agricultural Project 2006 lines of the Upper Midwest of the United States. Two-rowed barley lines were from barley breeding program of North Dakota State University (ND2 = 96) and Busch Agricultural Resources LLC (BA2 = 64). Six-rowed barley lines were from barley breeding program of University of Minnesota (UM = 94), North Dakota State University (ND6 = 91), and Busch Agricultural Resources, LLC $($ BA6 = 31). continuous distribution for SFNB resistance was observed among the lines of both two-rowed and six-rowed subpopulations, indicating the quantitative nature of seedling resistance to SFNB (Fig. 1). However, the frequency distribution of the two-rowed subpopulation barley lines skewed toward susceptibility (Fig. 1). About $43 \%$ of barley genotypes were considered resistant in the six-rowed subpopulation, whereas only $13 \%$ of genotypes were considered resistant to SFNB in the two-rowed barley subpopulation (Fig. 2). The ND6 subpopulation had the highest number of SFNB resistant lines $(52 \%)$ while only $3 \%$ of genotypes showed a resistant reaction in the BA2 subpopulation (Fig. 2). The average SFNB disease severity of two-rowed and six-rowed subpopulations was 6.6 and 5.1, respectively (Table 1). The spot blotch resistant genotype NDB112 and the cultivar 'Harrington' were highly susceptible to SFNBM09 (infection response 7.8 and 8.4, respectively). The barley line CI9819, and the two cultivars 'Bowman' and 'Manchuria' showed SFNB resistance reactions with infection responses ranging from 2.0 to 3.7 (Table 1 ).

Marker coverage, $L D$, and population structure. There were $1,873,1,923$, and 2,028 SNP markers in the six-rowed subpopulation, two-rowed subpopulation, and combined six- and tworowed barley population, respectively, after filtering of the original 3,072 SNPs for $10 \%$ missing data and 5\% minor allele frequency (Table 2). The average genetic distances between all pairs of SNP markers was $0.71 \mathrm{cM}$. The PCA showed three distinct subgroups for the combined population. Two distinct groups were formed from two-rowed lines, one group by ND2 and another group by BA2 (Fig. 3). All six-rowed lines from ND6, UM, and BA6 were clustered together in one group. In association analysis, PCA was used as covariate to control false positives due to population structure of two-rowed and six-rowed subpopulations.

The LD estimates varied over different genomes. The genome wide average LD was 18,10 , and $10 \mathrm{cM}$ at $r^{2}=0.2$ for six-rowed subpopulation, two-rowed subpopulation, and combined populations, respectively (Table 2). LD decayed rapidly to $r^{2}=0.2$ within

TABLE 1. Spot form of net blotch seedling disease severity of the most resistant lines from six-rowed and two-rowed barley Coordinated Agricultural Project 2006 subpopulations

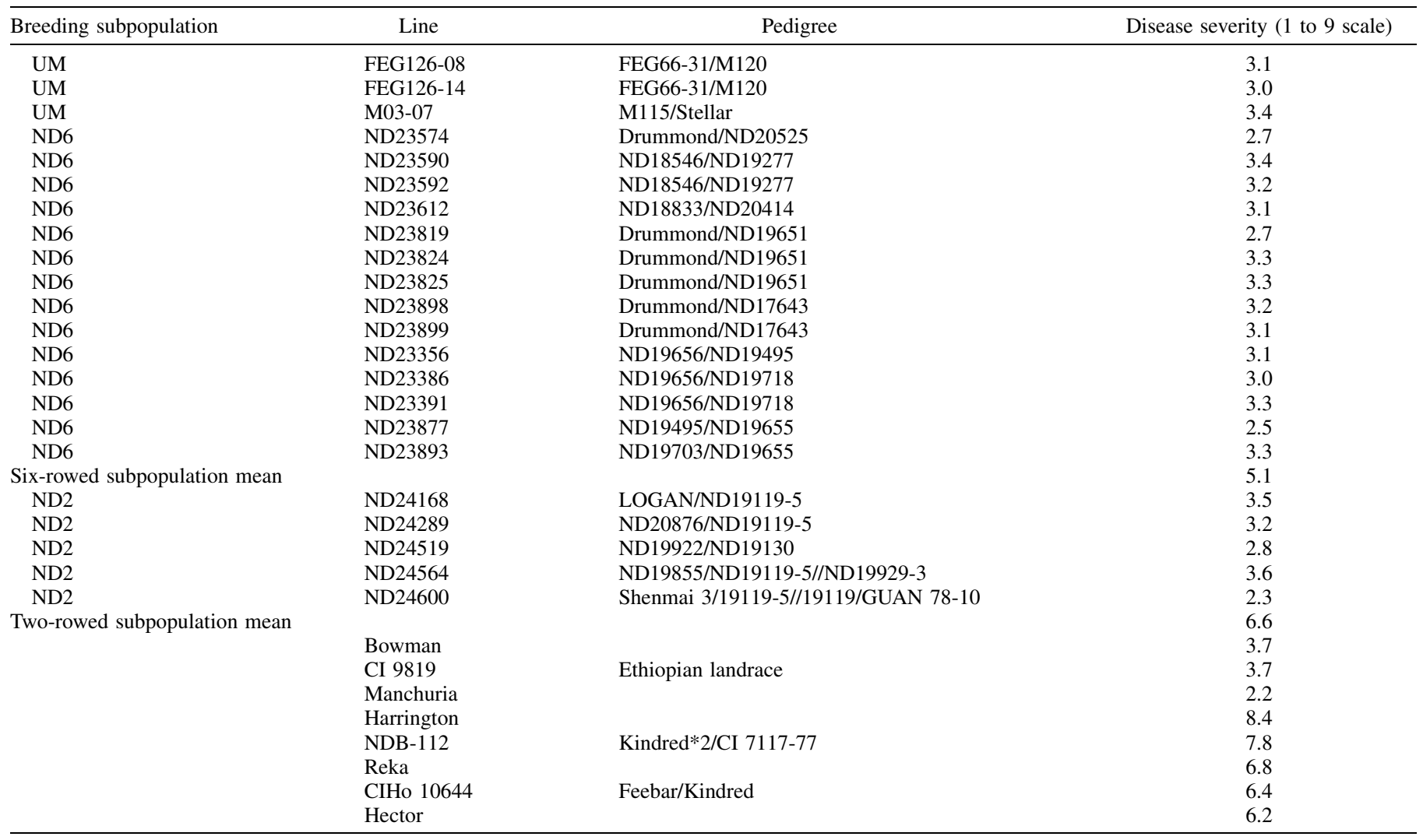


$10 \mathrm{cM}$ on chromosome $3 \mathrm{H}, 4 \mathrm{H}$, and $6 \mathrm{H}$; but expanded to between 10 to $15 \mathrm{cM}$ on chromosome $1 \mathrm{H}$ and $2 \mathrm{H}$. The $\mathrm{LD}$ decay data were used to declare QTL in different regions of the genome.

Marker-trait associations and identification of QTL. A conservative $P$ value threshold of $<0.001[-\log (p)]$ from MLM analysis and pFDR $(q<0.13)$ were used to declare significant SNPSFNB associations. Significant $-\log (p)$ value of significant SNPs across the barley genome is presented in Figure 4 for the combined population, the six-rowed and two-rowed subpopulations.

The MLM analysis identified 14, 3, and 6 significant SNPs $(P<$ $0.001)$ associated with SFNB resistance in the combined, sixrowed, and two-rowed populations, respectively (Table 3, Fig. 4). Allele frequencies and additive effect of all significant SNPs are presented in Table 3. Out of 14 significant SNPs, additive effect was negative for four markers and positive for 10 markers. The negative and positive additive values increase resistance and susceptibility, respectively. In the combined population, a total of 10 QTL (14 SNPs) associated with SFNB resistance were detected on chromosomes $2 \mathrm{HS}$, 3HL, 5HL, 6HS, and 7HS (Table 3). More than one SNP was detected in most of the QTL. Phenotypic variations $\left(R^{2}\right)$ explained by these QTL ranged from 1.4 to $4.3 \%$ (Table 3 ). All the QTL identified in the six-rowed and two-rowed subpopulations were also identified in the combined population. In the six-rowed subpopulation, only two QTL (three SNPs), SFNB-2H-8-10 and SFNB-6H-5.4 were identified, however the $S F N B-6 H-5.4$ QTL was declared a false positive in the FDR analysis. In the two-rowed subpopulation, six significant QTL (seven SNPs) associated with SFNB resistance were identified in the MLM analysis, however one of each on chromosomes $4 \mathrm{H}, 6 \mathrm{HS}$, and $7 \mathrm{HS}$ were declared a false positive in the FDR analysis (Table 3 ). The $R^{2}$ explained by these QTL ranged from 3.5 to $6.5 \%$.

The QTL $S F N B-2 H-8-10$ was associated with three SNP markers within a $2 \mathrm{cM}$ region on chromosome $2 \mathrm{H}$ and the marker 12_31497 was detected in all three populations and explained the highest $R^{2}$, 4.3 to $6.5 \%$, indicating this QTL could be tightly linked to a common SFNB resistance in the barley breeding programs. Three significant SNP markers 11_0243, 12_31011 and 12_31393 were located in the same genomic location at $58.64 \mathrm{cM}$ on chromosome 3HL (QTL SFNB-3H-58.64) indicating that these markers are cosegregating for SFNB resistance (Table 3).

\section{DISCUSSION}

Use of host resistance is an economically and environmentally benign option for SFNB management in barley. Compared with NFNB, SFNB was until recently not considered economically important in the United States and only a few SFNB resistance genes had been mapped. Most of the QTL were previously identified using biparental mapping approaches (Grewal et al. 2008, 2012; Manninen et al. 2006; Williams et al. 1999, 2003). Recent studies have also identified QTL using association genetics studies of core germplasm from a global collection (Tamang et al. 2015) and an Australian tworowed barley breeding population (Wang et al. 2015). To our knowledge, the present study is the first association mapping-based approach to identify SNP-SFNB resistance linkage using tworowed and six-rowed subpopulations from contemporary barley breeding programs in the United States. We used MLM in association analysis as it has more power to minimize false positives and to detect true association between markers and phenotypes compared with a general linear model (Patterson et al. 2006; Zhao et al. 2007).

Continuous distribution of infection responses of barley genotypes at seedling stage for SFNB in the mapping populations indicates the quantitative nature of SFNB resistance in the populations investigated. The quantitative nature of resistance for SFNB infection was also reported in previous studies from the United States and Australia (Friesen et al. 2006; Tamang et al. 2015; Wang et al. 2015; Williams et al. 1999). In this study, phenotypic evaluation showed high variability in SFNB resistance among barley lines from three breeding programs and barley row types. The numbers of barley lines resistant to SFNB were higher in sixrowed (43\%) compared with two-rowed subpopulations (13\%). PCA showed two separate clusters of two-rowed subpopulations, while six-rowed subpopulations from all three breeding programs (UMN, NDSU, and BARI) were in the same cluster (Fig. 3). Malysheva-Otto et al. (2006) found that two-rowed and six-rowed barley germplasm separated into different populations in their genetic diversity study. Among the six-rowed subpopulations from the different breeding programs, the NDSU six-rowed subpopulation had the greatest number of SFNB resistant lines (62\%) indicating the population contains many barley genotypes that

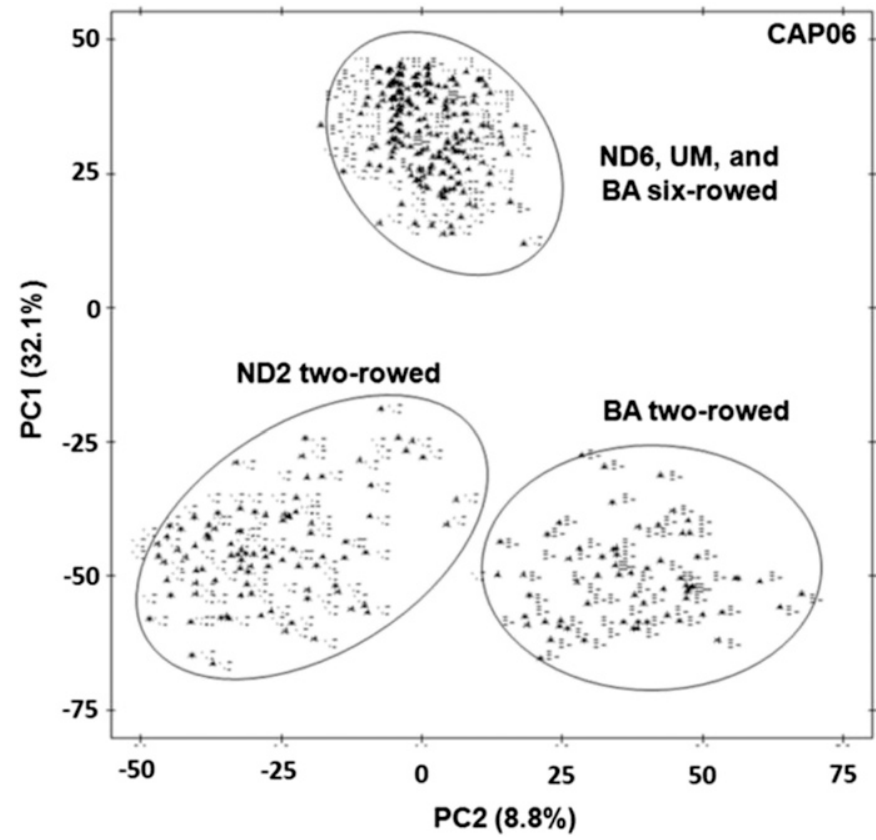

Fig. 3. Three subpopulations clustered as ND2 two-rowed, BA two-rowed barley, and six-rowed (ND6, UM, and BA) by principal component analyses. Two-rowed barley lines were from barley breeding program of North Dakota State University (ND2 = 96) and Busch Agricultural Resources LLC (BA2 = 64). Six-rowed barley lines were from barley breeding program of University of Minnesota (UM = 94), North Dakota State University (ND6 = 91), and Busch Agricultural Resources LLC (BA6 = 31).

TABLE 2. Single nucleotide polymorphism (SNP) markers used in association mapping in the barley Coordinated Agricultural Project 2006 population

\begin{tabular}{lcccccc}
\hline Population/subpopulation & $n^{\mathrm{a}}$ & $\mathrm{SNP}^{\mathrm{b}}$ & Average distance $(\mathrm{cM})^{\mathrm{c}}$ & Number of gaps $>5 \mathrm{cM}$ & Number of gaps $>10 \mathrm{cM}$ & Average LD $(\mathrm{cM}){ }^{\mathrm{d}}$ \\
\hline Two-rowed subpopulation & 160 & 1,923 & 0.62 & 14 & 2 & 10 \\
Six-rowed subpopulation & 216 & 1,873 & 0.64 & 11 & 0 & 18 \\
Combined population & 376 & 2,028 & 0.58 & 16 & 10 \\
\hline
\end{tabular}

a Number of barley lines evaluated for spot form of net blotch.

${ }^{b}$ Number of SNP markers used for marker trait association after filtering for $10 \%$ missing data and 5\% minor allele frequency.

c Average distance estimated between all pairs of adjacent SNP markers.

d Average linkage disequilibrium (LD) was calculated by making all pair-wise SNP comparisons for LD across the genome, and evaluating the moving average of $r^{2}$ values. A threshold of $r^{2}=0.2$ was used for LD. 
could be good sources of SFNB resistance (Fig. 2). Among the tworowed barley subpopulations from the different breeding programs, the numbers of SFNB resistance lines were higher in the NDSU two-rowed subpopulation (20\%) than the BARI (3\%) two-rowed subpopulation. PCA also showed that among the two-rowed lines the BARI two-rowed subpopulation clustered separately from the NDSU two-rowed subpopulation. Tekauz (1990) reported higher levels of resistance to SFNB in six-rowed barley cultivars compared with two-rowed barley cultivars, which is consistent with our findings, and it is possible that this is due to similar parents in the NDSU and Canadian breeding programs. In contrast, Wang et al. (2015) found that about 40 to $65 \%$ lines from two-rowed barley populations in Australia showed a resistant reaction to SFNB.

In this study, higher numbers of QTL were identified in the combined population compared with the six-rowed or two-rowed subpopulations that could be due to the greater power afforded by the larger sample size in the combined population. The two-rowed subpopulation had higher number of QTL compared with the six-rowed subpopulation, although number of SFNB resistant genotypes were higher in six-rowed than in two-rowed subpopulations. Overall, 10 QTL were identified on chromosomes $2 \mathrm{HS}, 3 \mathrm{HL}, 5 \mathrm{HL}, 6 \mathrm{HS}$, and $7 \mathrm{HS}$ in the combined population; three QTL were identified on chromosomes $2 \mathrm{HS}$, $3 \mathrm{HL}$, and 6HS in the two-rowed subpopulation; while only one QTL was identified on chromosome $2 \mathrm{HS}$ in the six-rowed subpopulation. FDR analysis $(q \leq 0.13)$ was used to eliminate false positively linked SNPs to SFNB resistance. Among the 10 QTL identified, four (SFNB$2 H-8-10$, SFNB-2H-38.03, SFNB-3H-78.53, and SFNB-3H-117.1) have not been reported in previous studies for SFNB resistance suggesting that these QTL are worthy of further investigation.

Two QTL associated with seedling resistance of SFNB were identified on chromosome 2HS. The QTL SFNB-2H-38.03 was
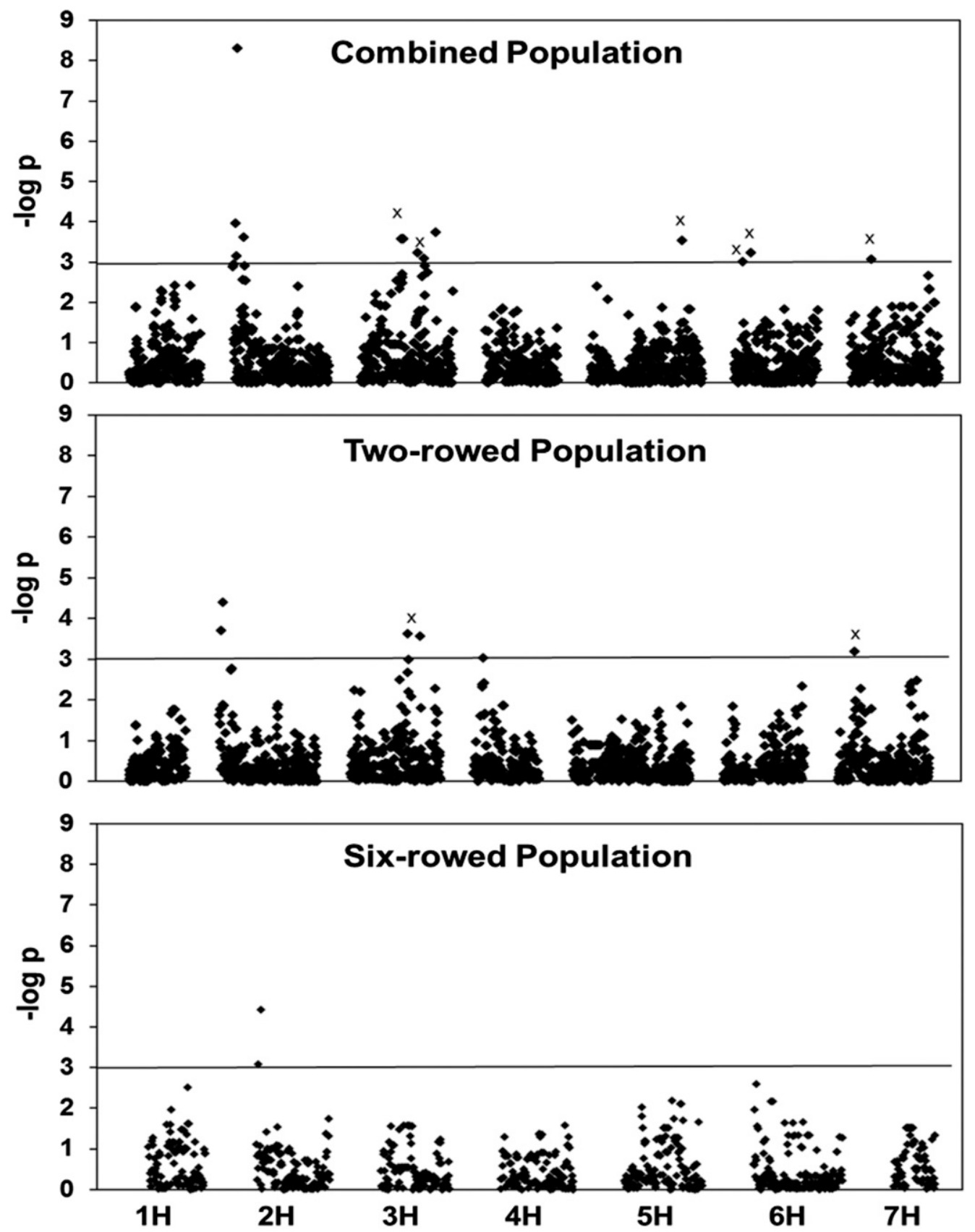

Fig. 4. Significant values $-\log (P)$ for single nucleotide polymorphisms (SNPs)-spot form of net blotch (SFNB) association in the barley Coordinated Agricultural Project 2006. Numbers of lines were 160 in two-rowed subpopulation, 216 in six-rowed subpopulation, and 376 in combined populations. A threshold of $-\log (P)=$ 3 is set to declare significant SNPs associated with SFNB resistance. $\times$ Location of previously published quantitative trait loci associated with SFNB resistance. 
identified in the combined population and the QTL SFNB-2H-8-10 was detected in the combined population and two-rowed and six-rowed subpopulations. The QTL SFNB-2H-8-10 has not been reported previously. Two SNP markers 12_31497 and 11_0530 located at 9.28 and $10.06 \mathrm{cM}$ on chromosome $2 \mathrm{H}(\mathrm{SFNB}-2 \mathrm{H}-8-10)$ showed high significant association with SFNB resistance $(P$ values of $<0.0001$ to $<0.00000001)$. The marker $12 \_31497$ was highly significantly correlated to SFNB resistance in the combined population (pFDR, $q<0.0001$ ), two-rowed (pFDR, $q=0.07$ ), and six-rowed subpopulations (pFDR, $q=0.03$ ). This marker explained the highest phenotypic variation $\left(R^{2}=4.3\right.$ to 6.5$)$ for SFNB resistance. The result suggests that $S F N B-2 H-8-10$ is an important QTL with very high association with SFNB resistance. The SNP 11_0578 located at $38.03 \mathrm{cM}$ on chromosome 2H (QTL SFNB-2H$38.03)$ was significantly associated with SFNB resistance. Wang et al. (2015) also identified QTL associated with SFNB resistance at $23.33 \mathrm{cM}$ on the chromosome $2 \mathrm{H}$, which is $15 \mathrm{cM}$ distant to the QTL $S F N B-2 H-38.03$ in our study. Therefore, $S F N B-2 H-38.03$ is considered as a new QTL.

The long arm of chromosome $3 \mathrm{H}$ harbors six SNPs (three QTL, $S F N B-3 H-78.53$, SFNB-3H-91.88, and SFNB-3H-117.1) significantly associated with SFNB resistance. Two SNPs, 11_0067 and 11_0289 located at $78.53 \mathrm{cM}(S F N B-3 H-78.53)$ and $91.88 \mathrm{cM}$ (SFNB-3H-91.88), explained 1.4 to $1.5 \%$ of phenotypic variations. The SNP 12_30927 located at $117.1 \mathrm{cM}(S F N B-3 H-117.1)$, explained $1.8 \%$ of phenotypic variation. Two QTL ( $S F N B-3 H-78.53$ and $S F N B$ $3 H-117.1$ ) on chromosome $3 \mathrm{H}$ reported in this study are unpublished QTL for SFNB resistance. Tamang et al. (2015) reported QTL associated with SFNB resistance on chromosome $3 \mathrm{H}$ at 99.26 to 99.66 $\mathrm{cM}$, which was about $9 \mathrm{cM}$ from the QTL SFNB-3H-91.88 and they may be the same QTL. The QTL SFNB-3H-58.64 was detected in the combined population and three significant SNP markers (11_0243, 12_31011, and 12_31393) were located at $58.64 \mathrm{cM}$, indicating that these markers are linked together and cosegregating for SFNB resistance. Wang et al. (2015) also reported QTL QRptms3.2 for SFNB resistance at $57.61 \mathrm{cM}$ on $3 \mathrm{HL}$, which is very close to the genomic region of QTL $S F N B-3 H-58.64$ and may be the same QTL. QTL associated with resistance to other diseases of barley have also reported on similar genomic region of the chromosome $3 \mathrm{H}$. Massman et al. (2011) using some of the same barley CAP population, reported SNP markers significantly associated with resistance for Fusarium head blight and deoxynivalenol at 42 to $65 \mathrm{cM}$ on the chromosome $3 \mathrm{H}$. Using a biparental mapping population, Graner et al. (1996) reported a major QTL $(P t a)$ resistance to NFNB at a similar genomic region to QTL $S F N B-3 H-78.53$ and $S F N B-3 H-91.88$. Spaner et al. (1998) also reported a major QTL associated with NFNB in this genomic region. QTL associated with Barley yellow mosaic virus and scald resistance were also reported in similar genomic regions of 3HL (Graner and Bauer 1993; Graner and Tekauz 1996; Williams et al. 2001). This is clearly a region rich in genes for resistance to a range of pathogens.

The SNP 11_1516 located at $155.13 \mathrm{cM}$ on chromosome $5 \mathrm{H}$, which was significantly associated with SFNB resistance (pFDR, $q=0.063$ ), is close to the genomic region of SFNB resistance QTL QRptm5-4 reported by Wang et al. (2015). Manninen et al. (2006) and Williams et al. (2003) also identified major QTL associated with SFNB resistance on the short arm of chromosome 5H. Rpt6, a seedling resistance gene was located at about $38 \mathrm{cM}$ on $5 \mathrm{H}$ (Manninen et al. 2006) and two QTL for adult plant resistance were located between 20 and $40 \mathrm{cM}$ on $5 \mathrm{H}$.

Chromosome $6 \mathrm{H}$ harbors important QTL responsible for both spot type and net blotch resistance. Two SNPs 11_0260 and $11 \_1170$ located at 5.4 and $33.74 \mathrm{cM}$ on chromosome 6HS (SFNB6H-5.4 and SFNB-6H-33.74) showed significant association with SFNB resistance. These markers explained 1.4 and $1.5 \%$ of phenotypic variation. Wang et al. (2015) also reported QTL QRptm6-1 at $12.70 \mathrm{cM}$ on $6 \mathrm{H}$, which is close to the QTL SFNB6H-5.4 in our study. Cakir et al.

TABLE 3. Significant quantitative trait loci (QTL) single nucleotide polymorphism (SNP) markers, their position, and their phenotypic variation associated with seedling resistance to spot form of net blotch (SFNB) in the Coordinated Agricultural Project 2006 barley population

\begin{tabular}{|c|c|c|c|c|c|c|c|c|c|}
\hline QTL/SNP markers & $\begin{array}{l}\text { SNP } \\
\text { marker }\end{array}$ & Chromosome & $\begin{array}{l}\text { Position } \\
\quad(\mathrm{cM})\end{array}$ & $P$ value & $\begin{array}{c}\text { FDR } \\
(\mathrm{Q} \text { value })\end{array}$ & $R^{2}(\%)$ & $\begin{array}{c}\text { Allele } \\
\text { frequency }\end{array}$ & $\begin{array}{l}\text { Additive } \\
\text { effect }^{\mathrm{a}}\end{array}$ & References $^{\mathrm{b}}$ \\
\hline \multicolumn{10}{|l|}{ Combined population } \\
\hline \multirow[t]{3}{*}{$S F N B-2 H-8-10$} & $11 \_0530^{\mathrm{c}}$ & $2 \mathrm{HS}$ & 9.28 & $1.09 \mathrm{E}-04$ & 0.0623 & 1.9 & 214 & 1.01 & \\
\hline & $12 \_30155$ & $2 \mathrm{HS}$ & 10.06 & 7.10E-04 & 0.114 & 1.5 & 205 & -0.631 & \\
\hline & $12 \_31497^{\mathrm{d}}$ & $2 \mathrm{HS}$ & 10.06 & 4.89E-09 & $<0.0001$ & 4.3 & 197 & -1.06 & \\
\hline$S F N B-2 H-38.03$ & 11_0578 & $2 \mathrm{HS}$ & 38.03 & $2.43 \mathrm{E}-04$ & 0.0623 & 1.7 & 85 & 0.595 & \\
\hline \multirow[t]{3}{*}{$S F N B-3 H-58.64$} & $11 \_0243$ & $3 \mathrm{HL}$ & 58.64 & $2.67 \mathrm{E}-04$ & 0.0623 & 1.7 & 161 & 0.78 & Wang et al. 2015 \\
\hline & 12_31011 & $3 \mathrm{HL}$ & 58.64 & $2.67 \mathrm{E}-04$ & 0.0623 & 1.7 & 161 & 0.78 & \\
\hline & 12_31393 & $3 \mathrm{HL}$ & 58.64 & $2.67 \mathrm{E}-04$ & 0.0623 & 1.7 & 161 & 0.78 & \\
\hline$S F N B-3 H-78.53$ & $11 \_0067$ & $3 \mathrm{HL}$ & 78.53 & $5.91 \mathrm{E}-04$ & 0.104 & 1.5 & 213 & -0.926 & \\
\hline$S F N B-3 H-91.88$ & $111_{-0289^{c}}$ & $3 \mathrm{HL}$ & 91.88 & $8.23 \mathrm{E}-04$ & 0.116 & 1.4 & 211 & 0.115 & Tamang et al. 2015 \\
\hline$S F N B-3 H-117.1$ & $12 \_30927^{\mathrm{c}}$ & $3 \mathrm{HL}$ & 117.1 & $1.81 \mathrm{E}-04$ & 0.0623 & 1.8 & 215 & 0.698 & \\
\hline$S F N B-5 H-155.13$ & 11_1516 & $5 \mathrm{HL}$ & 155.13 & $2.82 \mathrm{E}-04$ & 0.0623 & 1.7 & 41 & -0.503 & Wang et al. 2015 \\
\hline SFNB-6H-5.4 & $110_{0260^{\mathrm{d}}}$ & $6 \mathrm{HS}$ & 5.40 & $9.74 \mathrm{E}-04$ & 0.123 & 1.4 & 200 & 1.15 & Wang et al. 2015 \\
\hline SFNB-6H-33.74 & $11 \_1170$ & $6 \mathrm{HS}$ & 33.74 & $5.77 \mathrm{E}-04$ & 0.100 & 1.5 & 183 & 0.665 & Cakir et al. 2011 \\
\hline$S F N B-7 H-34.82$ & $12 \_30083^{c}$ & $7 \mathrm{HS}$ & 34.82 & $8.60 \mathrm{E}-04$ & 0.116 & 1.4 & 214 & 0.087 & $\begin{array}{l}\text { Tamang et al. 2015; Wang et al. 2015; } \\
\text { Williams et al. 1999, } 2003\end{array}$ \\
\hline \multicolumn{10}{|c|}{ Two-rowed subpopulation } \\
\hline \multirow[t]{2}{*}{ SFNB-2H-8-10 } & $11 \_0530^{\mathrm{c}}$ & $2 \mathrm{HS}$ & 9.28 & $1.95 \mathrm{E}-04$ & 0.12 & 4.5 & 132 & 0.808 & \\
\hline & $12 \_31497^{d}$ & $2 \mathrm{HS}$ & 10.06 & $4.03 \mathrm{E}-05$ & 0.07 & 6.5 & 88 & 0.89 & \\
\hline$S F N B-3 H-91.88$ & $11 \_0289^{c}$ & $3 \mathrm{HL}$ & 91.88 & $2.33 \mathrm{E}-04$ & 0.12 & 4.4 & 106 & 0.964 & Tamang et al. 2015 \\
\hline$S F N B-3 H-117.1$ & $12 \_30927^{c}$ & $3 \mathrm{HL}$ & 117.10 & $2.74 \mathrm{E}-04$ & 0.12 & 4.3 & 122 & 0.828 & \\
\hline$S F N B-4 H-36.37$ & 11_1262 & $4 \mathrm{HS}$ & 36.37 & $9.27 \mathrm{E}-04$ & 0.26 & 3.5 & 129 & -0.613 & \\
\hline$S F N B-6 H-5.4$ & $11 \_0260^{\mathrm{d}}$ & $6 \mathrm{HS}$ & 5.40 & $9.00 \mathrm{E}-0.3$ & 0.84 & 3.5 & 135 & 0.313 & Wang et al. 2015 \\
\hline$S F N B-7 H-34.82$ & $12 \_30083^{\mathrm{c}}$ & $7 \mathrm{HS}$ & 34.82 & $6.30 \mathrm{E}-04$ & 0.23 & 3.8 & 110 & -0.696 & $\begin{array}{l}\text { Tamang et al. 2015; Wang et al. 2015; } \\
\text { Williams et al. 1999, } 2003\end{array}$ \\
\hline \multicolumn{10}{|c|}{ Six-rowed subpopulation } \\
\hline \multirow[t]{2}{*}{ SFNB- $2 \mathrm{H}-8-10$} & 12_10592 & $2 \mathrm{HS}$ & 8.57 & $8.05 \mathrm{E}-04$ & 0.363 & 3.2 & 202 & -1.02 & \\
\hline & $12 \_31497^{\mathrm{d}}$ & $2 \mathrm{HS}$ & 10.06 & $3.73 \mathrm{E}-05$ & 0.03 & 4.8 & 197 & -1.06 & \\
\hline SFNB-6H-5.4 & $11 \_0260^{\mathrm{d}}$ & $6 \mathrm{HS}$ & 5.40 & $4.55 \mathrm{E}-04$ & 0.5 & 3.5 & 200 & 1.15 & Wang et al. 2015 \\
\hline
\end{tabular}

a Negative and positive values indicate markers contributing to resistance and susceptibility, respectively.

b Previously published QTL associated with resistance to spot form of net blotch.

c Significant markers identified in two-rowed and combined mapping population.

d Significant markers identified in six-rowed, two-rowed, and combined mapping population. 
(2011) identified QTL for both seedling and adult plant resistance for SFNB in a Baudin/AC Metcalfe doubled haploid population with the resistance coming from the Australian cultivar Baudin and mapped to $23.9 \mathrm{cM}$ on chromosome $6 \mathrm{H}$. This location is close to the marker SNP $11 \_1170$, which is located at $33.7 \mathrm{cM}$ on chromosome $6 \mathrm{H}$, suggesting that it is possible that these are the same QTL. St. Pierre et al. (2010) reported major QTL resistance to NFNB on Bin 2 and Bin 6 (42 to 46 $\mathrm{cM}$ ) of chromosome $6 \mathrm{H}$. Grewal et al. (2008) reported a major QTL (QRpts6) associated with SFNB resistance at a different genomic region on $6 \mathrm{H}$ (75 to $78 \mathrm{cM}$ ). QTL associated with resistance of other barley diseases such as scald (Abbott et al. 1995) and powdery mildew (Backes et al. 1995) were reported to be nearby the QTL on 6HS identified in our study.

The SNP marker 12_30083 located at $34.82 \mathrm{cM}$ on chromosome $7 \mathrm{H}$ was significantly associated with SFNB resistance in the CAP06 combined population and two-rowed subpopulation. Tamang et al. (2015) and Wang et al. (2015) also reported QTL associated with SFNB resistance in nearby genomic regions $(26.35$ to $27.71 \mathrm{cM})$ on 7H. Williams et al. $(1999,2003)$ reported a major gene, $R p t 4$, at 40 to $45 \mathrm{cM}$ on chromosome $7 \mathrm{H}$ and the locus explained $80 \%$ of phenotypic variability for SFNB resistance. The SNP 12_30083 in our study is close to Rpt4. Several major QTL associated with spot blotch resistance have also been reported in a similar genomic region of 7H (Bilgic et al. 2005; Roy et al. 2010; Yun et al. 2005).

The size and structure of population, marker density, and extent of LD will affect the detection of marker trait association and resolution of mapping (Hamblin et al. 2010; Wang et al. 2015). Using a more diverse set of lines from the barley CAP and creating different sized populations by subsampling, Wang et al. (2012) found inconsistent and false association of marker and trait in small mapping populations. However, the population size used in our study was shown to be theoretically adequate to detect SNP-SFNB associations. To further protect against spurious associations, in our study, PCA was performed to detect population structure and minimize false positive association. In addition, genome-wide association mapping has been shown to be an adequate method of identifying marker trait association in a crop species like barley with extensive LD (Hamblin et al. 2010). The extensive LD in barley CAP populations is due to domestication and breeding (Hamblin et al. 2010). In our study, LD decayed within 10 to $15 \mathrm{cM}$ on chromosomes $3 \mathrm{H}, 6 \mathrm{H}$, and $2 \mathrm{H}$, where higher numbers of significant SNPs associated with SFNB resistance were identified. LD is important for setting the minimum distance apart that QTLs need to be to have confidence in them being declared as an independent QTL.

The traditional biparental mapping approach was used previously for mapping QTL associated with SFNB resistance and most of them identified major QTL explaining high (6 to 84\%) phenotypic variability (Cakir et al. 2011; Friesen et al. 2006; Grewal et al. 2008; Manninen et al. 2006; Williams et al. 1999). In many cases the QTL identified in our study are close to QTL identified in these biparental mapping populations and further work is needed to confirm whether the QTL in this study are allelic to the previously described QTL. In contrast to biparental mapping, phenotypic variation explained by significant SNPs in our study is smaller (1.4 to $6.5 \%$ ) possibly because there has been no active attempt in the U.S. barley breeding programs to accumulate resistance genes for SFNB and no passive selection pressure to maintain the genes in the population. Low phenotypic variation associated with multiple QTL is a fundamental characteristic of association mapping. The probability of detecting large effect QTL will be higher in biparental mapping since these populations are normally developed from parents that differ widely in the trait being investigated. In GWAS using the barley CAP population, Massman et al. (2011) and Gyawali (2010) also reported low percentage of the phenotypic variation $\left(R^{2}=1\right.$ to $3 \%$ ) explained by QTL associated with resistance for Fusarium head blight or resistance to common root rot. Similarly, Tamang et al. (2015) also reported low phenotypic variation $\left(R^{2}<4 \%\right)$ in their GWAS of SFNB resistance in an international collection of barleys. In recent GWAS, low explanation of phenotypic variations has also been found for QTL associated with tan spot, Stagonospora nodorum resistance in wheat (Adhikari et al. 2011; Gurung et al. 2011), and spot blotch resistance in a wild barley population (Roy et al. 2010).

The genes conditioning resistance to the two forms of net blotch appear to be different and it is possible that there could be a differential reaction to different isolates of SFNB so that location specific selection and screening programs need to be in place for this disease in barley breeding. Previously SFNB was not considered as economically important disease of barley in the United States and there was no active development of SFNB resistant barley cultivars. Within the breeding programs servicing the Upper Midwest barley growing areas, in 2006 programs which would be the source of cultivars currently being released, about $15 \%$ of sixrowed barley breeding lines and 5\% of two-rowed barley breeding lines are moderately resistant or better to SFNB (Fig. 1). This indicates that the barley breeding program in the Midwest needs to quickly devote effort to developing SFNB resistance. The SNPs showing high significant association with SFNB resistance in our study can be utilized in barley breeding programs targeted for SFNB resistance without having to introduce unadapted material into the programs. A strong relationship between seedling and adult stage resistance has been reported for both SFNB and NFNB in barley (Grewal et al. 2008; Williams et al. 1999) with occasional QTL being identified that are associated with either seedling or adult plant resistance alone (Wang et al. 2015). QTL associated with seedling resistance for SFNB are often linked to adult plant resistance. As the QTL identified only explain a low percentage of the phenotypic variation, it is proposed that the identified QTL are validated in new populations created for this purpose and that the new populations are also screened for adult plant resistance. With markers now able to be created for marker-assisted selection, the value in reducing yield loss of individual QTL and QTL combinations can be assessed in the field and elite breeding highly resistant parents can be created and utilized in barley breeding programs.

\section{ACKNOWLEDGMENTS}

This study was supported by the barley CAP (USDA9 CSREES-NRI grant 2006-55606-16722) and the American Malting Barley Association.

\section{LITERATURE CITED}

Abbott, D. C., Lagudah, E. S., and Brown, A. H. D. 1995. Identification of RFLPs flanking a scald resistance gene of barley chromosome 6. J. Hered. 86:152-154. Adhikari, T. B., Jackson, E. W., Gurung, S., Hansen, J. M., and Bonman, J. M. 2011. Association mapping of quantitative resistance to Phaeosphaeria nodorum in spring wheat landraces from the USDA National Small Grains Collection. Phytopathology 101:1301-1310.

Backes, G., Graner, A., Forough-Wehr, B., Fischbeck, G., Wenzel, G., and Jahoor, A. 1995. Localization of quantitative trait loci (QTL) for agronomic important characters by the use of a RFLP map in barley (Hordeum vulgare L.). Theor. Appl. Genet. 90:294-302.

Bilgic, H., Steffenson, B. J., and Hayes, P. 2005. Differential expression of seedling and adult plant resistance to spot blotch in different genetic backgrounds of barley. Theor. Appl. Genet. 111:1238-1250.

Bockelman, H. E., Sharp, E. L., and Bjarko, M. E. 1983. Isolates of Pyeronphora teres from Montana and the Mediterranean region that produce spot-type lesions on barley. Plant Dis. 67:696-697.

Bradbury, P. J., Zhang, Z., Kroon, D. E., Casstevens, T. M., Ramdoss, Y., and Buckler, E. S. 2007. TASSELL Software for association mapping of complex traits in diverse samples. Bioinformatics 23:2633-2635.

Cakir, M., Gupta, S., Li, C., Hayden, M., Mather, D. E., Ablett, G. A., Platz, G. J., Broughton, S., Chalmers, K. J., Loughman, R., Jones, M. G. K., and Lance, R. C. M. 2011. Genetic mapping and QTL analysis of disease resistance traits in the barley population Baudin $\times$ AC Metcalfe. Crop Pasture Sci. 62:152-161.

Campbell, G. F., Crous, P. W., and Lucas, J. A. 1999. Pyrenophora teres f. maculata, the cause of Pyrenophora leaf spot of barley in South Africa. Mycol. Res. 103:257-267. 
Close, T. J., Bhat, P. R., Lonardi, S., Wu, Y., Rostoks, N., Ramsey, L., Druka, A., Stein, N., Svensoon, J. T., Wanamaker, S., Bozdag, S., Roose, M. L., Moscou, M. J., Chao, S., Varshney, R. K., Szûcs, P., Sato, K., Hayes, P. M., Matthews, D. E., Kleinhofs, A., Muehlbauer, G. J., DeYoung, J., Marshall, D. F., Madishetty, K., Fenton, R. D., Condamine, P., Garner, A., and Waugh, R. 2009. Development and implementation of high-throughput SNP genotyping in barley. BMC Genomics 10:582.

Friesen, T. L., Farsi, J. D., Lai, Z., and Steffenson, B. J. 2006. Identification and chromosomal location of major genes for resistance to Pyrenophora teres in a doubled-haploid barley population. Genome 49:855-859.

Graner, A., and Bauer, E. 1993. RFLP mapping of the ym4 virus resistance gene in barley. Theor. Appl. Genet. 86:689-693.

Graner, A., Foroughi-Wehr, B., and Tekauz, A. 1996. RFLP mapping of a gene in barley conferring resistance to net blotch (Pyrenophora teres). Euphytica 91:229-234.

Graner, A., and Tekauz, A. 1996. RFLP mapping in barley of a dominant gene conferring resistance to scald (Rhynchosporium secalis). Theor. Appl. Genet. 93:421-425.

Grewal, T. S., Rossnagel, B. G., Pozniak, C. J., and Scoles, G. J. 2008. Mapping quantitative trait loci associated with barley net blotch resistance. Theor. Appl. Genet. 116:529-539.

Grewal, T. S., Rossnagel, B. G., and Scoles, G. J. 2012. Mapping quantitative trait loci associated with spot blotch and net blotch resistance in a doubledhaploid barley population. Mol. Breed. 30:267-279.

Gupta, P. K., Rustgi, S., and Kulwal, P. L. 2005. Linkage disequilibrium and association studies in higher plants: Present status and future prospects. Plant Mol. Biol. 57:461-485.

Gurung, S., Mamidi, S., Bonman, J. M., Jackson, E. W., del Rio, L. E., Acevedo, M., Mergoum, M., and Adhikari, T. B. 2011. Identification of novel genomic regions associated with resistance to Pyrenophora triticirepentis races 1 and 5 in spring wheat landraces using association analysis. Theor. Appl. Genet. 123:1029-1041.

Gyawali, S. 2010. Association mapping of common root rot and spot blotch diseases of barley and population genetics of Cochliobolus sativus. Ph.D. Dissert., North Dakota State University, Fargo, ND.

Hamblin, M. T., Close, T. J., Bhat, P. R., Chao, S., Kling, J. G., Abraham, K. J., Blake, T., Brooks, W. S., Cooper, B., Griffey, C. A., Hayes, P. M., Hole, D. J., Horsley, R. D., Obert, D. E., Smith, K. P., Ullrich, S. E., Muehlbauer, G. J., and Jannink, J.-L. 2010. Population structure and linkage disequilibrium in U.S. barley germplasm: Implications for association mapping. Crop Sci. 50:556-566.

Hayes, P., and Szucs, P. 2006. Disequilibrium and association in barley: Thinking outside the glass. Proc. Natl. Acad. Sci. 103:18385-18386.

Karki, C. B., and Sharp, E. L. 1986. Pathogenic variation in some isolates of Pyrenophora teres f. sp. maculata on barley. Plant Dis. 70:684-687.

Kraakman, A. T. W., Niks, R. E., van den Berg, P. M. M. M., Stam, P., and Van Eeuwijk, F. A. 2004. Linkage disequilibrium mapping of yield and yield stability in modern spring barley cultivars. Genetics 168: 435-446.

Liu, Z. H., Ellwood, S. R., Oliver, R. P., and Friesen, T. L. 2011. Pyrenophora teres: Profile of an increasingly damaging barley pathogen. Mol. Plant Pathol. 12:1-19.

Liu, Z. H., and Friesen, T. L. 2010. Identification of Pyrenophora teres $\mathrm{f}$. maculata, causal agent of spot type net blotch of barley in North Dakota. Plant Dis. 94:480.

Louw, J. P. J., Crous, P. W., and Holz, G. 1996. Relative importance of the barley net blotch pathogens Pyrenophora teres f. teres (net-type) and P. teres f. maculata (spot-type) in South Africa. Afr. Plant Prot. 2:89-95.

Lynch, M., and Ritland, K. 1999. Estimation of pairwise relatedness with molecular markers. Genetics 152:1753-1766.

Malysheva-Otto, L. V., Ganal, M. W., and Roder, M. S. 2006. Analysis of molecular diversity, population structure and linkage disequilibrium in a worldwide survey of cultivated barley germplasm (Hordeum vulgare L.). BMC Genet. 7:6.

Manninen, O. M., Jalli, M., Kalendar, R., Schulman, A., Afanasenko, O., and Robinson, J. 2006. Mapping of major spot type and net type net blotch resistance genes in the Ethiopian barley line CI9819. Genome 49: 1564-1571.

Massman, J., Cooper, B., Horsley, R., Neate, S., Dill-Macky, R., Chao, S., Dong, Y., Schwarz, P., Muehlbauer, G. J., and Smith, K. P. 2011. Genomewide association mapping of Fusarium head blight resistance in contemporary barley breeding germplasm. Mol. Breed. 27:439-454.
McLean, M. S., Howlett, B. J., and Hollaway, G. J. 2009. Epidemiology and control of spot form of net blotch (Pyrenophora teres f. maculata) of barley: A review. Crop Pasture Sci. 60:303-315

Mikel, M. A., and Kolb, F. L. 2008. Genetic diversity of contemporary North American barley. Crop Sci. 4:1399-1407.

Patterson, N., Price, A. L., and Reich, D. 2006. Population structure and eigenanalysis. PLoS Genet. 2:e190.

Pritchard, J. K., and Przeworski, M. 2001. Linkage disequilibrium in humans: Models and data. Am. J. Hum. Genet. 69:1-14

Roy, J. K., Smith, K. P., Muehlbauer, G. J., Chao, S., Close, T. J., and Steffenson, B. J. 2010. Association mapping of spot blotch resistance in wild barley. Mol. Breed. 26:243-256.

Slotta, T. A. B., Brady, L., and Chao, S. 2008. High throughput tissue preparation for large scale genotyping experiments. Mol. Ecol. Resour. 8:83-87.

Spaner, D., Shugar, L. P., Choo, T. M., Falak, I., Briggs, K. G., Legge, W. G., Falk, D. E., Ullrich, S. E., Tinker, N. A., Steffenson, B. J., and Mather, D. E. 1998. Mapping of disease resistance loci in barley on the basis of visual assessment of naturally occurring symptoms. Crop Sci. 38:843-850.

St. Pierre, S., Gustus, C., Steffenson, B., Dill-Macky, R., and Smith, K. P. 2010. Mapping net form net blotch and Septoria speckled leaf blotch resistance loci in barley. Phytopathology 100:80-84.

Steffenson, B. J., Olivera, P., Roy, J. K., Jin, Y., Smith, K. P., and Muehlbauer, G. J. 2007. A walk on the wild side: Mining wild wheat and barley collections for rust resistance genes. Aust. J. Agric. Res. 58:532-544.

Storey, J. D. 2002. A direct approach to false discovery rates. J. R. Stat. Soc. B 64:479-498.

Tamang, P., Neupane, A., Mamidi, S., Friesen, T., and Brueggeman, R. 2015. Association mapping of seedling resistance to spot form net blotch in a worldwide collection of barley. Phytopathology 105:500-508.

Tekauz, A. 1985. A numerical scale to classify reactions of barley to Pyrenophora teres. Can. J. Plant Pathol. 7:181-183.

Tekauz, A. 1990. Characterization and distribution of pathogenic variation in Pyrenophora teres f. teres and P. teres f. maculata from western Canada. Can. J. Plant Pathol. 12:141-148.

Tuohy, J. M., Jalli, M., Cooke, B. M., and O'Sullivan, E. 2006. Pathogenic variation in populations of Drechslera teres f. teres and D. teres f. maculata and differences in host cultivar responses. Eur. J. Plant Pathol. 116:177-185.

Turkington, T. K., Tekauz, A., Xi, K., and Kutcher, H. R. 2011. Foliar diseases of barley: Don't rely on a single strategy from the disease management toolbox. Prairie Soil Crop J. 4:142-150.

van den Berg, C. G. J., and Rossnagel, B. G. 1991. Epidemiology of spot type net blotch on spring barley in Saskatchewan. Phytopathology 81:1446-1452.

Wang, H., Smith, K. P., Combs, E., Blake, T., Horsley, R. D., and Muehlbauer, G. J. 2012. Effect of population size and unbalanced data sets on QTL detection using genome-wide association mapping in barley breeding germplasm. Theor. Appl. Genet. 124:111-124.

Wang, X., Mace, E. S., Platz, G. J., Hunt, H. H., Hickey, L. T., Franckowiak, J. D., and Jordan, D. R. 2015. Spot form of net blotch resistance in barley is under complex genetic control. Theor. Appl. Genet. 128:489-499.

Waugh, R., Jannick, J.-L., Muehlbauer, G. J., and Ramsay, L. 2009. The emergence of whole genome association scans in barley. Curr. Opin. Plant Biol. 12:218-222.

Williams, K., Bogacki, P., Scott, L., Karakousis, A., and Wallwork, H. 2001. Mapping of a gene for leaf scald resistance in barley line 'B87/14' and validation of microsatellite and RFLP markers for marker-assisted selection. Plant Breed. 120:301-304.

Williams, K. J., Lichon, A., Gianquitto, P., Kretschmer, J. M., Karakousis, A., Manning, S., Langridge, P., and Wallwork, H. 1999. Identification and mapping of a gene conferring resistance to the spot form of net blotch (P. teres f. maculata) in barley. Theor. Appl. Genet. 99:323-327.

Williams, K. J., Platz, G. J., Barr, A. R., Cheong, J., Willsmore, K., Cakir, M., and Wallwork, H. 2003. A comparison of the genetics of seedling and adult plant resistance to spot form of net blotch (Pyrenophora teres f. maculata). Aust. J. Agric. Res. 54:1387-1394.

Yun, S. J., Gyenis, L., Hayes, P. M., Matus, I., Smith, K. P., Steffenson, B. J., and Muehlbauer, G. J. 2005. Quantitative trait loci for multiple disease resistance in wild barley. Crop Sci. 45:2563-2572.

Zhao, H. H., Fernando, R. L., and Dekkers, J. C. M. 2007. Power and precision of alternate methods for linkage disequilibrium mapping of quantitative trait loci. Genetics 175:1975-1986.

Zhu, C., Gore, M., Buckler, E. S., and Yu, J. 2008. Status and prospects of association mapping in plants. Plant Genome 1:5-20. 